Textures and Microstructures, 1988, Vols. 8 \& 9, pp. 611-617

Reprints available directly from the publisher

Photocopying permitted by license only

C) 1988 Gordon and Breach Science Publishers Inc.

Printed in the United Kingdom

\title{
Texture Dependent Young's Modulus in Austenitic Cladding
}

\section{G. HOFER}

Kraftwerk Union, Hammerbacher Str 12 \& 14, PF 3220, D-8520, Erlangen, FRG

(Received 27 July 1982; in final form 13 August 1987)

Dedicated to the memory of Professor Günter Wassermann

In Austenitic claddings of pressure vessel steel columnar grains with a $\langle 100\rangle$-fiber axis oriented perpendicular to the surface have been previously observed. The fiber axis is parallel to the steepest temperature gradient. Since high temperature gradients also exist in the plane of cladding, preferred orientation should be found there.

This was proved with $\{111\}$ - and $\{220\}$-pole figures taken of the cladding in addition to $\{200\}$-pole figures. From these pole figures it could be concluded that the cladding has a $\{100\}\langle 110\rangle$-texture. The sharpness of the texture decreases from the surface of the cladding toward the base material.

Low values of Young's modulus measured in the cladding could be explained by comparing the texture with single crystal data of Young's modulus of Ni.

KEY WORDS: Pressure vessels, Austenitic steel, claddings, pole figures, Young's modulus, anisotropy, columnar grains.

\section{INTRODUCTION}

Pressure vessels are frequently cladded with Austenitic material as protection against corrosion. Columnar crystals oriented perpendicular to the surface of the cladding are formed (Hofer and Bender, 1980) during rapid cooling after the cladding process. This is similar to the formation of columnar crystals during casting of fcc-material $(\mathrm{Hu}, 1974)$. In both cases $\langle 100\rangle$-fiber textures have been observed. The fiber axis is parallel to the steepest temperature 


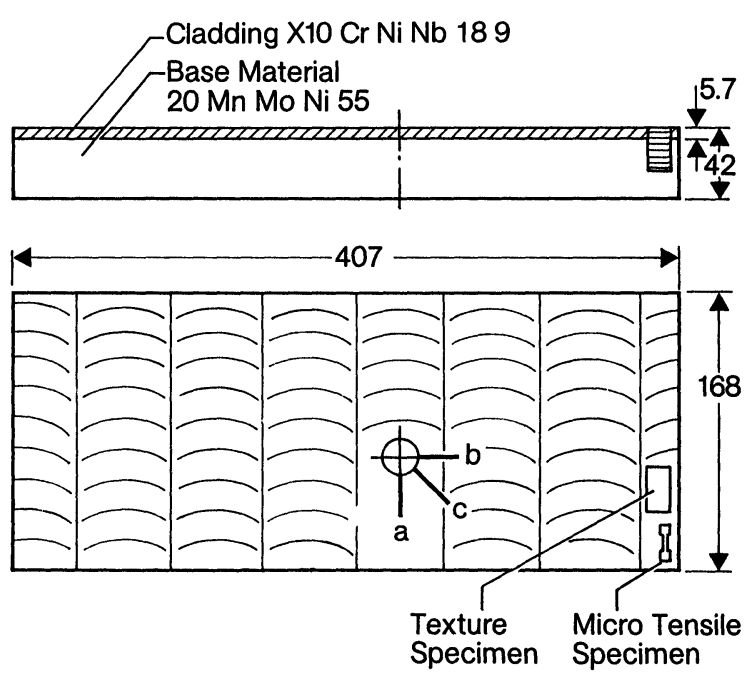

Figure 1 Cladding, measuring position, directions of strain measurement and positions of texture and micro tensile specimens.

gradient. High temperature gradients also exist in the plane of cladding. Therefore, it has been suggested (Hofer and Bender, 1980) that preferred orientation also should be found in the plane perpendicular to the fiber axis. For this reason, a detailed texture analysis was performed on an Austentitically strip cladded block of pressure vessel steel (Figure 1).

Very low values of Young's modulus of down to $100,000 \mathrm{~N} / \mathrm{mm}^{2}$ have been measured in Austenitic claddings (Hofer and Bender, $1977 ; 1980)$. Orientation dependent velocities of sound have been observed in model Austenitic weldments containing large columnar grains (Kolb and Wölfel, 1975). Minima of velocity of sound were found in the $\langle 100\rangle$-directions. In order to correlate textures with the elastic property of the Austenitic cladding investigated, Young's modulus was measured as a function of depth.

\section{EXPERIMENTAL DETAILS}

Texture specimens $(25 \times 15 \times 1 \mathrm{~mm})$ were taken from the position indicated in Figure 1 at depths of 1.0, 2.5, 4.0 and $5.5 \mathrm{~mm}$. The 

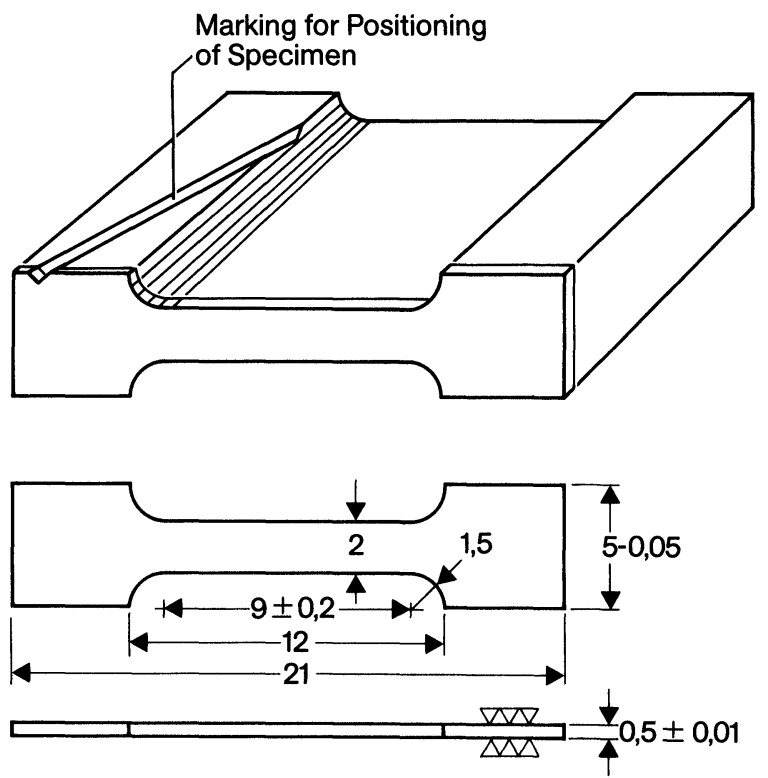

Figure 2 Profiled block and micro tensile specimen (Klausnitzer, 1976).

samples were sectioned by electro-discharge cutting and chemically etched to remove machining strains.

Micro tensile specimens (Klausnitzer, 1976) were electrodischarge machined from a profiled sample (Figure 2) taken from the cladded block. They were precision ground and etched chemically to remove machining strains. The micro tensile specimens were loaded in a low load tensile testing machine. Strains were measured with the aid of strain gauges applied to both sides of the specimens.

$\{111\}-,\{200\}-$ and $\{220\}$-pole figures were determined on a computer-controlled Lücke texture goniometer (Hofer, Günes and Hung, 1977) using $\operatorname{CoK} \alpha$-radiation.

\section{RESULTS OF TEXTURE MEASUREMENTS}

Figure 3 shows $\{200\}$-pole figures as a function of depth in the Austenitic cladding investigated. From these pictures it could be 


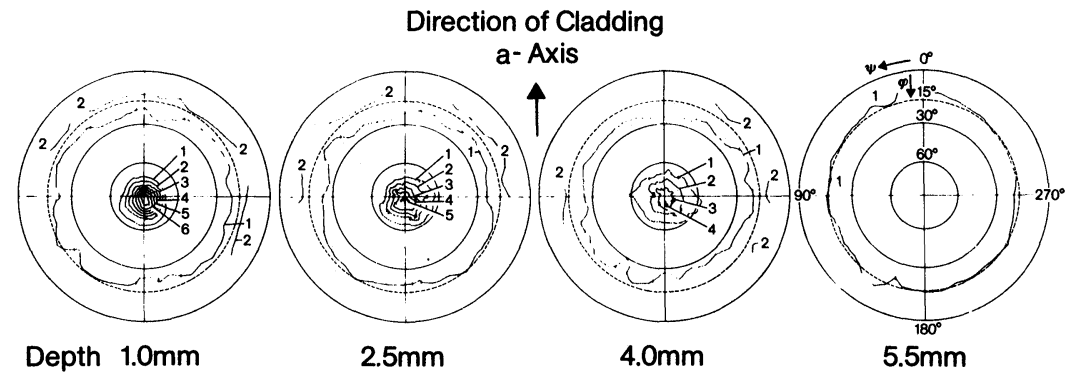

Figure $3\{200\}$-pole figures as a function of depth in an Austenitic cladding.

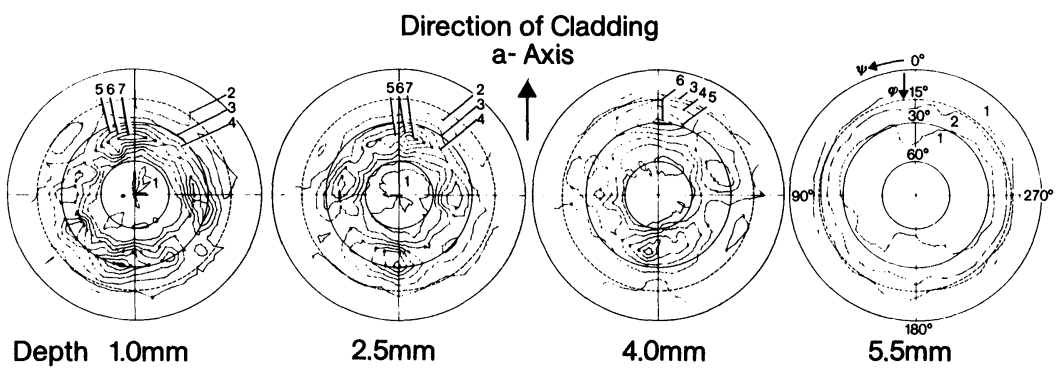

Figure $4\{111\}$-pole figures as a function of depth in an Austenitic cladding.

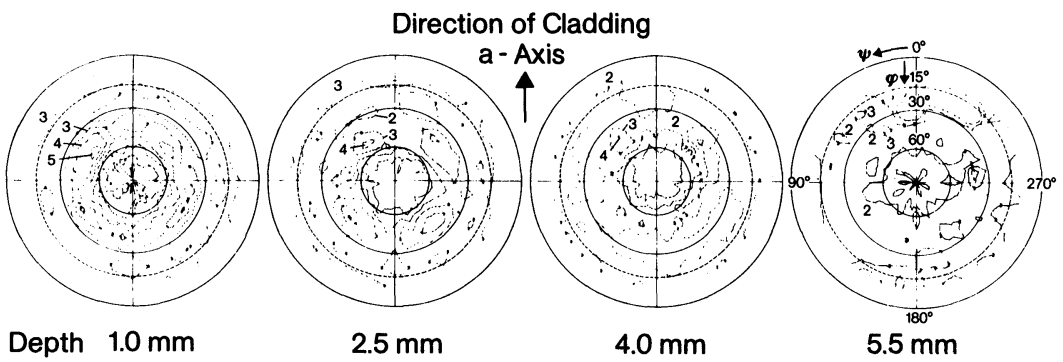

Figure $5\{220\}$-pole figures as a function of depth in an Austenitic cladding. 


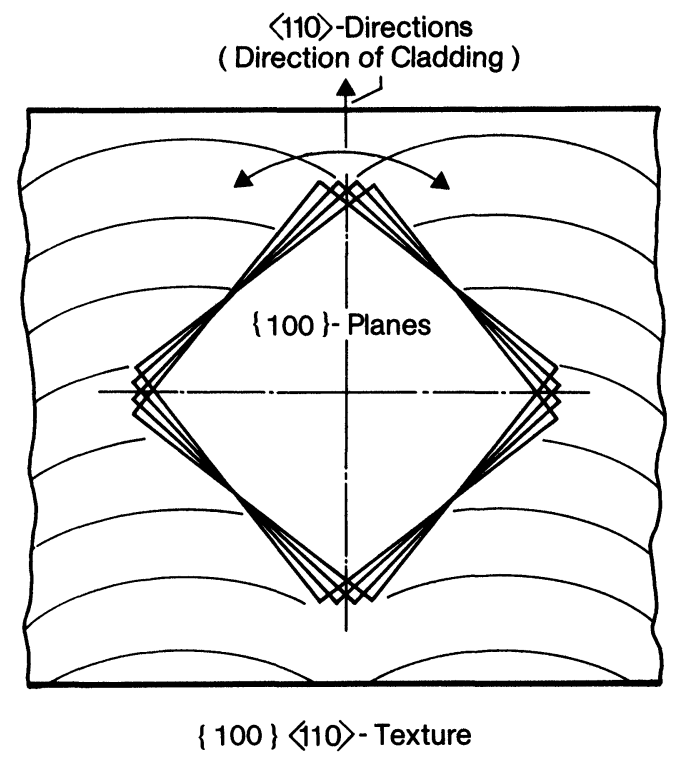

Figure 6 Orientation of fcc-cubic Austenite crystals in cladding.

concluded that the cladding has a $\langle 100\rangle$-fiber texture with the fiber axis perpendicular to the plane of cladding. The intensity of the texture is decreasing with depth. The $\{111\}-$, and $\{220\}$-pole figures, however, indicate that there exists preferred orientation also in the plane of cladding (Figures 4 and 5). The intensity of these pole figures is also decreasing with depth.

From the $\{111\}$ - and $\{220\}$-pole figures on may conclude that the $\langle 110\rangle$-directions of the columnar crystallites are oriented preferentially in the direction of the process of cladding as shown in Figure 6. The cladding thus exhibits a $\{100\}\langle 110\rangle$-texture.

\section{RESULTS OF MEASUREMENT OF YOUNG'S MODULUS AND DISCUSSION}

Very low values of Young's modulus are measured in the Austenitic cladding (Figure 7). The values are decreasing from the surface to 


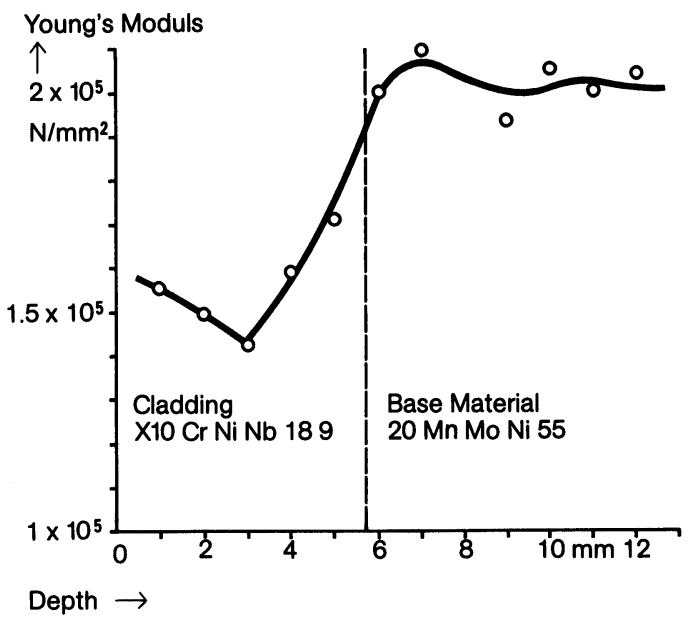

Figure 7 Young's moduls of elasticity as a function of depth in cladding and base material.
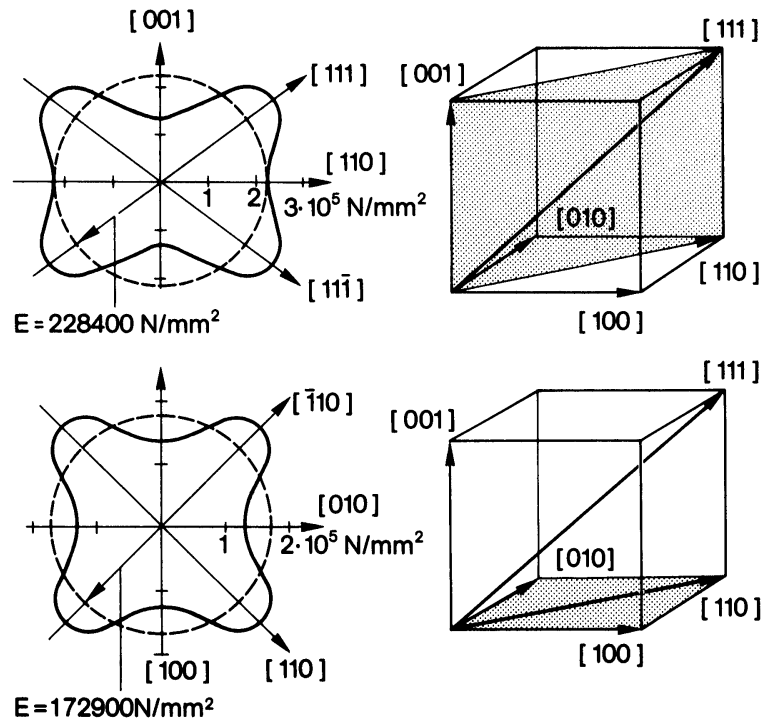

Figure 8 Directional dependence of Young's modulus in fcc-cubic Ni-single crystals. Average values taken from Metals Reference Book (Smithells, 1967). 
the center of the cladding and then increasing toward the fusion line where they reach the values of the base material.

The directional dependence of Young's modulus (Smithells, 1967) in single crystal $\mathrm{Ni}$ representing a typical fcc-material is shown in Figure 8. One can see from the bottom diagram of Figure 8 that the crystallographic directions within the $\{100\}$-planes have lower values of Young's modulus than all other directions. This could explain the low values observed in the micro tensile specimens taken parallel to the cladding and to its $a$-axis (Figure 1), because $\{100\}$-planes are preferentially found to lie parallel to the plane of cladding (Figure 6).

The intitial decline of Young's modulus with depth (Figure 7) may be explained with the decrease in sharpness of the texture (Figure 3). The surface range of the cladding with the sharper texture contains more crystallites with $\langle 110\rangle$-directions with higher Young's modulus parallel to the cladding and testing direction than the center of the cladding. The increase of Young's modulus near the fusion line is due to mixing base material and Austenitic cladding.

\section{References}

Hofer, G. and Bender, N. (1977). The Measurement of Residual Stresses in Claddings, Welding Institute Reprint, Paper 40, Proceedings of the Conference on Residual Stresses in Welded Construction and their Effects, London 15-17, November 1977, pp. 89-96. London: Welding Institute.

Hofer, G. and Bender, N. (1980). Eigenspannungsmessungen an Plattierungen verschiedener Herstellungsverfahren. In Eigenspannungen, proceedings of a Symposium in Bad Neuheim 1979, pp. 69-93. Oberursel: Deutsche Gesellschaft für Metallkunde.

Hofer, G., Günes, Ü., Hung, C. C. (1977). On-line Plotting of X-Ray Pole Figures with a Lücke Texture Goniometer Controlled by a Desk-Top Computer, Siemens Forschungs- und Entwicklungs-Ber., 6, 346-349.

$\mathrm{Hu}$, Hsun (1974). Texture of Metals. Texture, 1, 233-258.

Klausnitzer, E. (1976). Entwicklung eines Verfahrens zur Entnahme und Prüfung von Mikro-Flachzugproben aus der Wärmeeinflußzone von Schweißverbindungen. Materialprüfung, 18, 411-416.

Kolb, K. and Wölfel, M. (1975), Zur Ultraschallprüfung von KernreaktorDruckbehältern. Materialprüfung, 17, 352-358.

Smithells, C. J. (1967). Metals Reference Book, Vol. III, 4th Edition p. 710, London: Butterworths. 